\section{Physics in Industry in the United States}

THe Advisory Council on Applied Physics of the American Institute of Physics met at the University Club, Pittsburgh, Pa., on November 16. This was the inaugural meeting of this Council, the purpose of which is to stimulate the application of physics by recommending suitable actions and policies to the Institute and the founder societies. Dr. Paul D. Foote, executive vice-president of the Gulf Research and Development Corporation, presided during the morning session and Dr. Lyman J. Briggs, director of the Bureau of Standards, during the afternoon. A discussion was held on the university education and training of men whose careers are to lie in industrial research. This discussion was opened with reports by Dr. Saul Dushman (presented by Dr. A. W. Hull) of the General Electric Co. and Prof. George H. Harrison of the Massachusetts Institute of Technology. Further discussion was devoted to the services which are rendered by the founder societies and the Institute to physicists employed in industrial laboratories. Reports on this topic were presented by Dr. L. O. Grondahl, director of research, Union Switch and Signal Co., and Prof. John T. Tate, of the University of Minnesota. In this connexion, the Council passed a resolution encouraging the formation by such physicists of a division on applied physics of the Physical Society. It is strongly felt that, while the Optical Society, the Acoustical Society and the Society of Rheology furnish splendid facilities for meetings and publications in their fields, other general applications of physics are neglected. The opinion of the Council is opposed to the formation of new specialised societies, since only through close integration with the Physical Society can the community of interest and interchange of ideas between the general applications and the basic fundamentals of physics be conserved.

\section{South Indian Bronzes at South Kensington}

Bronze figures of the members of the Hindu Pantheon in their various manifestations are a conspicuous feature in the art of southern India. Of these, there is a large collection in the Madras Government Museum, which is perhaps not so widely known in detail as it deserves. The iconographic value of these bronzes is great : they are an important source of information for Hindu religious and cosmological conceptions; but, as a rule, their artistic merit is not high. It is now announced that, by a bequest of the late Lord Ampthill, formerly Governor of the Madras Presidency, the Victoria and Albert Museum, South Kensington, has acquired five of these bronzes, which are both of high artistic merit and of interest for their religious significance. Of these the most important is a figure of Siva as the Cosmic Dancer, which expresses the idea that the god himself is both performer and audience, while the universe is his theatre. The figure is four-armed, and appears in a dancing attitude in an encircling flaming nimbus. In its upper hands are a drum and fire as the symbols of creation and destruction respectively, while the lower hands are in the conventional attitudes of protection and assuranee. The headdress includes a crescent moon, a human skull, cobras and flowers. The male and female principles are signified by a man's ear-ring in the right ear and a woman's ear-ring in the left ear. With this figure is shown one of his consort Parvati, in the manifestation of Gauri. These figures were found buried near a temple in the Tinevally District of the Madras Presidency. They were made by the cire perdue process; and from their stylistic affinities it is concluded that they belong to the late tenth or early eleventh century of our era. Lord Ampthill's bequest, part of which had previously been on loan in the museum, includes, in addition to the five bronzes, a number of other objects of great interest, illustrative of Brahmanical and Buddhist beliefs.

\section{Vision in Optical Instruments}

IN his Thomas Young Oration of the Physical Society on December 6, Prof. Charles Fabry discussed "Vision in Optical Instruments". Classical theory gives the resolving power of an optical instrument as determined by diffraction phenomena, but the result so obtained takes no account of the properties of the eye. Consequently, it does not indicate exactly what will actually be perceived with an instrument. What can actually be seen with such an instrument depends considerably on the brightness of the object examined, and on the degree of contrast between its parts and between the object and the background. In order to examine these questions, it is necessary to commence with the properties of the eye, and in particular, its ability to distinguish objects, not under the ideal conditions reached in the laboratory, but under conditions similar to those met with during observations. The effect of brightness is particularly large : for the greatest brightness the limit of resolution is about $\mathbf{l}^{\prime}$, whilst it is 250 times as large (about $4^{\circ}$ ) for barely perceptible brightness. Contrast also has a very large effect. With these data, it becomes possible to determine what the eye will really see in a given instrument, assumed to be of perfect geometrical construction. The optimum size of exit-pupil can be calculated, and is found to be $0.7 \mathrm{~mm}$. for the highest illumination, in agreement with experience. For an instrument with geometrical imperfections, an efficiency can be defined characterising the qualities of this instrument as compared with those of a perfect instrument. Stray light (fog) is another cause of inferiority in instruments, and the effect of this factor was discussed by Prof. Fabry.

\section{Automatic Fire and Burglar Alarms}

A Device, invented in France, which can be used either as a fire alarm which will give automatically a telephone message to the fire brigade, or as a burglar alarm which will summon the police, is described in The Times of December 7. The apparatus is called a 'signaphone', and is already installed in about forty buildings in Paris. When used as a fire alarm, the device is operated either by thermostats fixed near the ceiling, or by push buttons so that a watchman has only to press the nearest button. The thermostats are operated by hot air rising to the 
ceiling when fire breaks out. This breaks a closed electric circuit, and an electrical relay at once starts a clockwork motor. The motor drives a small dialling drum, the small metal discs on which correspond to the letters and figures of the telephone number of the nearest fire station. The station is thus called up and a gramophone record then comes into action giving, in a verbal message, the location of the fire and all essential details. This message is repeated continuously for $3 \frac{1}{2}$ minutes. If necessary, also, it can be made to ring up a second number-for example, that of the owner of the building-and repeat its message. When used as a burglar alarm, the signaphone is connected with an electric circuit in the building. In this case, a burglar who opens a door or window, takes down a picture or tries to open a safe or desk, without knowing it thereby summons the police, who learn from the the gramophone message what is happening. Anyone who desires to have both a fire and burglar alarm must have two signaphones installed. The Post Office has given permission for these devices to be attached to telephones on automatic exchanges. It has also met with the approval of the Metropolitan Police, to whom it has been demonstrated.

\section{Equalising Supply and Demand}

IN the first number of Trends-A Monthly Graphical Review of Business Movements (H. Whitehead and Staff, 20 Buckingham Gate, S.W.1, October 1935), Mr. Harold Macmillan contributes an interesting article on "Equalising Supply and Demand" in which he emphasises the importance of planning an adjustment of productive effort, so as to ensure the production of all goods and services in the quantities which will enable them to exchange for one another at prices covering their production costs. The regulation of production in relation to demand for the products of each industry requires that some common policy should be pursued by all the units collectively, for example, in regard to scientific research, observance of standard wages and conditions, maintenance of standards of quality or standardisation of the range of patterns. But as things are, a common policy must depend on voluntary agreements, and in the great majority of cases voluntary agreements break down because, when they have created conditions of stability and profit. ability, other producers are attracted who can exploit the market by the old methods. Mr. Macmillan therefore urges that it is necessary to give industry legal powers to enforce upon a recalcitrant minority decisions which have been approved by a large majority of the producers and have been sanctioned by Parliament. It is essential, however, that there should be adequate safeguards to defend the general public interest and the special interests of consumers and workers affected in each case.

\section{Despotic and Democratic Governments}

THE question as to whether parliamentary democracy can survive its present crisis and whether the rise of dictatorships in Italy, Germany and Russia does not indicate the decline of a long epoch of parliamentary government, is discussed by $\mathrm{Mr}$. Herbert W. Stewart in an article in the Hibbert Journal (April, 1935). Mr. Stewart definitely rejects the modern scepticism, although he is far from denying many of the difficulties and real dangers involved in the parliamentary system, such as party intrigues, the corruption of the free but corruptible Press, the demagogic misuse of public institutions under parliamentary control. The unavoidable dilemma of this system seems to be that current affairs are run either by expert commissions, more or less on account of the initiative of the electorate and its parliamentary representatives-or by the masses themselves, and this involves the danger of delicate political matters becoming dependent on the issue of demagogical party activities and political bargainings.

ComparIng these dangers with those of Fascist States, however, Mr. Stewart concludes that Fascist State policy is apt to replace a comparative evil by a much more radical one ; for an oligarchy controlling the key positions of the State is worse than the personal power of local cliques under parliamentary government. Parliamentary corruption is the smaller evil as compared with the possible and hidden corruption under a despotic government. The disadvantages of democratic governments should not be over-stressed. In the United States, Canada and Great Britain, after all, the individual voter does not feel that the electoral victory of any one of the existing parties might jeopardise the country. Parliamentary institutions are capable of adapting themselves to new circumstances and of modifying themselves. In the long run, the masses do not wish to be without these means of self-expression.

\section{Solar Activity and Radio Transmission}

Recentuy, Dr. J. H. Dellinger, head of the radio section of the Bureau of Standards at Washington, suggested that a close watch should be kept to see whether there was a fade-out of radio transmissions at any time between October 21 and 25. He was led to make this suggestion by the discovery of severe fading occurring on March 20, May 12, July 6 and August 30, which indicate a 54-day cycle. Accord. ing to a report issued by Science Service, Washington, D.C., certain short wave-lengths were wiped out by eruptions of the sun for the single day October 24 . This fade-out sheds new light on the difficult problem of the connexion between radio transmission, sunspots and magnetic storms. Ordinary transmissions having wave-lengths approximately the same as those used in domestic broadcasting were not affected; but experimental radio transmission was completely wiped out, and the sending of commercial and amateur radiograms was greatly hampered.

The Bureau of Standards describes the occurrence on October 24 as a wiping out of radio transmission above a certain frequency. It is also stated that there was probably some eruption in the sun much more sudden than the growth of a sunspot, and that this abruptly changed the rate at which the sun 